\title{
Give full play to the advantages of school sports management and promote the development of national fitness
}

\author{
Kang Jian \\ Xijing University, Xi'an, 710123, China
}

Keywords: physical education, national fitness, teaching reform

\begin{abstract}
The implementation of the national fitness program is related to the national physical quality and promotes the development of social civilization to a higher level. It has profound significance in promoting the modernization construction of socialist and thriving of the Chinese nation. But on the basis of the current situation of our country, it is very difficult to achieve the goal that by the end of the century initially build a complete national fitness system with Chinese characteristics, expand the number of sports activities, generally improve national physical fitness, the national physical quality and the main indexes of mass sports reach or exceed the medium developed countries by the middle of the next century. It is a difficulty, complex system engineering. It is mainly to set up the correct sports idea, strengthen the consciousness of national fitness and build full fitness content and method. Make the masses to master of fitness themselves. So the physical education has become an important part of the national fitness. Youth has become the key object of the national fitness, the importance of school physical education will also be showed up. So, the national fitness program, must make the students feel the fun of sports, so as to improve the students' initiative in physical exercise. But the current school physical education in China exists the blind pursuit of short-term benefits, too much emphasis on students' practical exercise. The physical and educational goal focused only on the physical status of students during the period of school physical education, therefore the PE class becomes a quality test class, lacking of the cultivation of the students of the interest in sports, hobbies, consciousness, independent and the self training ability. Therefore, our sports teaching must be reformed, fully mobilize the enthusiasm of students. Only become the master of the classroom, can students truly learn sports skills, techniques, and master the methods of scientific physical exercise, and benefit of a lifetime. Only in this way, can school sports and fitness combine together, to enhance people's constitution in the true sense, improve the quality of life.
\end{abstract}

\section{Introduction}

School sports is the foundation of national sports, to seize the school sports is to seize the whole Chinese physical. Therefore, the school sports investment should arouse our attention, school sports investment is the main problem, the sports interest, time and material. In this regard, the school sports teaching should focus on the cultivation of students' physical exercise the skills, so that they gradually form a conscious habit of physical exercise, to make students fully aware of whether to obtain health or to get mental health, physical exercise should be as "not what others want me to practice, but for the highly conscious action of health conscious practice", firmly establish lifelong sports The concept of physical exercise in an important position in the development of life. So we should make the school sports teaching reform, change the concept of teaching, transfer the teaching focus, focus on improving students' physical ability. To ensure the normal school physical teaching under the premise of whether the school extracurricular sports activities and the content of national fitness and process combination is the fundamental task of the development stage of school physical education. School physical education will promote the sports development towards a good direction, while the national fitness campaign in depth, will accelerate the further reform of school physical education, realize the real meaning of fitness.

The so-called national fitness, is able to provide a basic environment of physical fitness and conditions continue for all citizens, meet the basic needs of all the national physical fitness, so that all the national health service and guarantee system significantly improved. The school sports is the 
foundation of community sports, family sports. To make the "National fitness program has been the development of a virtuous cycle the school sports to put in the position of strategic focus. This is because in the process of implementing fitness plan, people need to exercise, you need to master the methods and means, methods and means of the need for education and time. Only the school sports can make people receive good physical education, organized, There are plans to cultivate people lifelong sports attitude and ability, to make the educated love sports, independent, voluntary participation in sports in promoting physical and mental development at the same time, to create natural labor, enjoy the nature of the pleasure of sports and sports, the sports culture become the indispensable content of future life, at the same time to encourage more people to participate in sports, which play a key role in the national fitness program at the beginning of specific implementation.

\section{National fitness in physical education should be reflected}

\section{Update concepts, enhance national fitness awareness}

Due to the progress of science and technology and modern production development, people's physical exercise and also gradually reduced, and the number of people in China do not participate in physical exercise. So "modern civilization syndrome" is also a rising trend in the development of our country. With the social progress and development, people's understanding of health is also constantly updated, although no one unified strict definition, but at least they began to abandon the "disease not see a doctor, is healthy" wrong understanding, changing from the simple understanding of the biological model of human health for the bio psycho social medical model. Comprehensive WHO. Definition: health but no physical defects and diseases, but also have Complete physical, psychological and social adaptation ability. Therefore, health is not just sick, it should include the normal physiological, psychological and mental state of social adaptability. Health is the pursuit of the lofty goal of everyone, but also the basic guarantee for a country to achieve modernization, health is an important symbol of social progress and potential power, achieve health level as high as possible is an important social goal in the world. Therefore, health promotion is the common responsibility of society, so that everyone who exercise is to make China's comprehensive national strength to improve the performance. The United States President Clinton pointed out that health is the twenty-first Century "pass" all over the world. Without exception, the government focused on mass sports. Young people should be the main force to carry out the national fitness program in China, they have neither the old people that leisurely mentality and abundant leisure time, and no young people in school conditions and lively psychology. Therefore, to strengthen their national consciousness and the sense of urgency to sense of responsibility, strengthening propaganda and education. Many people always use a variety of reasons and excuses for not participating in physical exercise and to defense, this is essentially the idea and awareness of the problem, but also on the living standards of high quality lack of modern consciousness, needs to be clarified and update the concept.

\section{Training qualified sports talents is the basis of national fitness}

The training of qualified personnel for twenty-first Century. The coordinated development of physical and mental fitness plan is a huge scale, involving one billion and three hundred million people big plans, plan pointed out: "children and adolescents is the owner of the twenty-first Century, their healthy growth is related to national prosperity and national prosperity. School sports is the foundation of national sports, school sports caught is to seize the whole Chinese physical. However, for a long time in our school in the" examination oriented education "under the guidance of the idea, the school adopted a closed or semi closed, filled, high business education mode, and less social contact, students not only knowledge and training out of the narrow. And the poor physical quality, almost no concept of lifelong sports consciousness, can not adapt to the construction of socialist modernization needs such as the April 29, 1949. Therefore, to change "examination oriented education" to "quality education", breaking the boundaries, schools and society open education, realize the socialization of school sports, the formation of "family, school, new mode of sports social common development. 


\section{Give full play to the advantages of school sports management, and promote the development of national fitness}

Our schools have sports teachers of nearly 100 thousand people, including high school sports teacher more than 20 thousand people, most of them are highly educated, have certain professional knowledge training experience, including strong dedication, theory of comprehensive, high level of training of human resources which is potentially a person with breadth of vision, engaged in the National Fitness Activities Guidance and management. As long as give full play to their role, fitness will flourish along the healthy and upward road development. School physical education should be in the form of innovation, content and methods, one thing we can't ignore is that the habit is very important, which requires the teaching mode innovation, diversification, vivid. To study for the study, in the course of time will make interest, how to develop exercise habits. Combined with quality education, to further improve the status of school physical education, which requires the school physical education should vigorously carry out various sports activities, let students to think, in the activities to experience the physical and mental health, fitness will only get all-round development. Rest, entertainment, and sports can feel in life importance. With the progress of society and the improvement of living standards and the vigorous development of fitness, sports and recreational activities of the new projects are constantly emerging. Young people love fashion, of course, love sports and emerging Recreational sports. Therefore, our teaching contents should be pay attention to buying these items, like skating, climbing, aerobics, wheelbarrow movement of every hue, enrich the teaching content of physical education school. Through school physical education not only teach sports knowledge, but also teach the ideas, cultivate all-round development of people regardless of who. and a good foundation for the body is a teenager lay. So we have to let more students love sports, physical exercise consciously. The sports become an indispensable part of their life. Good habits are gradually develop, good health and long forging Refine the results

Fitness is the whole society, it involves many contents, contact a wide range of fitness, beauty, entertainment, sports, education, political, economic and social exchanges and other functions, a formal project, there are traditional folk sports, exercise and so on. We can to the recruitment of professional and specialized exercise training; will be organized for professional guidance, achieve the purpose of exercise, play professional proficiency in a particular line.

\section{National fitness program and physical education reform}

\section{Main problems in school sports}

The social demand for sports, calling for the reform of school physical education. In order to better implement the national fitness program, must make the students feel the fun of sports, so as to improve the students' initiative physical exercise. But the current school sports in our country generally have short-term benefits of blind pursuit of the goal of physical education, emphasize the students' practical exercise. One will enhance the physical education goal and focus only on the students during the school students' physical condition, physical education has transformed into a fitness test class, lack of students engaged in sports interest, hobbies, habits and culture consciousness and independent consciousness of exercise ability. The school sports teaching To also carry on classroom teaching, knowledge of books, mainly "teachers' leading role in the" three oriented "teaching mode. The teaching form is the most" command, imitation, three "teaching process", "to check the students' independent learning opportunities are rare, which caused the students to leave teachers to the society do not know how to exercise, how to keep fit, how to exercise self supervision.

\section{Basic ideas of physical education reform}

Strengthen the sports consciousness, establish the concept of lifelong sports. Independent student's sports consciousness directly affects the establishment of sports teaching efficiency and the concept of lifelong sports. For a long time, the student sports consciousness is weak, in order to change this situation, first let the students experience in sports fun, to inspire the learning interest of sports and recreation. The second is to create a sports atmosphere in the school, enable students to receive education in the nurture. Again to reform the sports competition system, strengthen the 
small variety, different levels, different levels, different levels, different items of interesting games, intelligent and physical combination game.

The reform of competitive sports as the main teaching materials, teaching system. The teaching syllabus of PE in sports items, materials difficult; two is to require each textbook technology high repetition and each grade textbook link meticulous serious, into the "cramming" teaching with textbooks and, seriously affected the enthusiasm of students in physical education is: three sports facilities to demand too much, most of the school is difficult to guarantee the quality and effect of teaching effect from the surface.

\section{Change the concept of teaching, promote national fitness}

The leading role of the traditional sports teaching emphasizes teacher, ignoring the main role of the students, the teacher is "holding their nose", students are always in a passive position, will only follow teachers behind imitate practice. This old concept of physical education, is not conducive to the cultivation of new talents in 90 s.

Therefore, in teaching reform of physical education, teachers should first change the old teaching idea, change from passive to active teaching. Teaching active teaching, the main role of the leading role and the student's teacher can give full play to students, from passive into active. Only the teachers to change the old teaching idea in order to fully mobilize the enthusiasm of the students, to become masters of the classroom, in order to truly learn sports skills, and can master the scientific method of exercise, the benefit for life.

The transfer of the teaching focus, put forward higher requirements for the implementation of primary and secondary schools focus on improving students' sports ability to establish the concept of lifelong sports and national fitness program: in addition to enhance the physical fitness of students, but also cultivate students' sports ability, the learning of fitness scientific method, to achieve sports independence. For a long time, our sports teaching emphasize the movement technology exquisite, its essence is the focus of teaching teaching and mastering sports techniques, and teaching difficult, unable to play its own. The student autonomy ability is poor. To change this situation, teaching should be the teaching focus on cultivating students' Sports ability, first asked the students to Move up, in the activities to stimulate students to learn music, and then through the combination of music and music learning, master of sports knowledge, skills, improve students' physical ability

\section{Conclusion}

(1) how to integrate the teaching content of school sports and extends to the national fitness activities, is currently the focus and difficulty of school physical education in China; in the form, to ensure the normal school physical teaching under the premise of whether the school extracurricular sports activities and fitness content and process the organic combination is the premise of school physical benefits with the long-term benefits of combining; in management, the students accept physical education at school has the corresponding measures, and the national fitness is from the heart, willing to participate in physical exercise.

(2) the organic integration of school physical education and national fitness can not only improve the students' awareness of physical exercise, but also promote the development of physical exercise habits.

(3) the development of school physical education will promote the fitness movement development towards a good direction, while the national fitness campaign in depth, will accelerate the further reform of school sports, school sports and fitness together organically, to enhance people's constitution in the true sense, improve the quality of life.

\section{References}

[1] Qu Yang. On the reform of China's college sports development and sports science conception [J]. 
[2] Zhang Xueliang. Comparison of physical education teaching mode in the United States, Japan, Russia and China [J] Journal of Tianjin University.

[3] National Fitness Program Outline .1995.6.

[4] Su Meiqing, Lu Qin. The cultivation of students' interest in sports [J]. Journal of Shanxi Normal University Institute of physical education.2000.

[5] Su Mei. Physical education psychology [M]. Beijing: Higher Education Press.1996.

[6] Lin Zhi. How to stimulate students' interest in physical education [J]. Journal of Yanan Institute of Education.

[7] Lin Zhicheng. In Chinese universities physical education elective investigation [J]. China sports science and technology.

[8] Gu Xuelan. Investigation and Analysis on the status quo of physical fitness and physical fitness of college students in China. Journal of Wuhan Sports Institute, 1996.

[9] Shi yan. Construction of sports teaching mode and teaching mode of sports Chinese comparative lack of [J]. Journal of Shenyang Sport University, 2005.

[10] Gu Jiuxian. Talk about how to cultivate students' interest in sports [J]. 2004 fourth mechanical occupation education.

[11] Ding Wenwu. To cultivate interest in physical education. North High School in Shenzhen Nanshan Branch Network and print the second period.

[12] Wang Lichong . How to cultivate interest in physical education [J]. Journal of Sports Adult Education.2003. 